\title{
Morphological, cultural, pathogenic and molecular studies of Alternaria brassicae infecting cauliflower and mustard in India
}

\author{
Manika Sharma ${ }^{1}$, Swati Deep ${ }^{1}$, Dinesh Singh Bhati ${ }^{1}$, P. Chowdappa ${ }^{2}$, R. Selvamani and \\ Pratibha Sharma ${ }^{1 *}$ \\ ${ }^{1}$ Plant Pathology, Indian Agricultural Research Institute, New Delhi, India. \\ ${ }^{2}$ Plant Pathology, Indian Institute of Horticultural Research, Bangalore, India.
}

Accepted 25 June, 2013

\begin{abstract}
Dark leaf spot (Alternaria brassicae) is one of the important diseases in crucifers causing serious yield and quality loss in production due to the seed borne nature of the pathogen. Variation in morphology and cultural characteristics among 32 representative Indian geographical isolates of Alternaria brassicae, the causal agent of Alternaria blight of cauliflower (Vegetable) rapeseed-mustard (Oil seed), was studied. All the isolates showed high level of variability in vitro in respect of conidial length, width, and number of septa. Conidia of Uttar Pradesh isolate (CaAbU4) were smallest in size with lowest number of septa. Substantial variation was found in mycelial growth, sporulation among these isolates in different nutrient media. All the isolates did not grow and sporulate abundantly on the same nutrient medium. However, Potato Dextrose Agar, Cauliflower (Host) Agar medium and Carrot Potato Agar were good for all the cultures. Variation in mycelial growth, sporulation was also observed. Cluster analysis of data on cultural variability among thirty two $A$. brassicae isolates found a close relationship among isolates of both origins viz, from Cauliflower and mustard. Isolates from Uttar Pradesh, Delhi, Haryana and West Bengal were found to be more similar to each other whereas the Rajasthan isolates along with Tamil Nadu and Kerala isolate were distantly related to others. All the isolates were pathogenic in nature but not directly related to the cultural and the morphological characteristics. These isolates were further molecularly characterized by using internal transcribed spacer region where all the isolates were found $56 \%$ similar to each other and $99 \%$ similar to the $A$. brassicae isolates present in NCBI database.
\end{abstract}

Key words: Dark leaf spot, Alternaria brassicae, morphology, cultural variability, pathogenicity, ITS analysis.

\section{INTRODUCTION}

Among several fungal diseases, severe damage of the foliage or seed germination in crucifers occurs due to Alternaria blight caused by Alternaria brassicae (Berk) (Tewari, 1983; Weiss, 1983; Kolte, 1985; Tewari, 1991; Verma and Saharan, 1994). Black spot of different crucifers viz-oil seed rape, cabbage, cauliflower and mustard have been reported in many countries; Italy (Tosi and Zazzerini, 1985), USA, UK and several other
European countries (Gladers, 1987), Canada (Berkenkamp and Kirkham, 1989; Conn and Tewari, 1990), Iran (Nourani et al., 2008) including India (Meena et al, 2010). Cauliflower (Brassicae oleracea var botrytis) and mustard (Brassicae juncea) are the two important crucifer crops of India which are facing serious yield and quality loss in production due to Alternaria brassicae (Berk) Sacc. causing dark leaf spot disease (Sharma et al., 2013). 
This species have the ability to survive in seeds for several months at different temperatures and relative humidity (Kumar and Gupta, 1994; Abul-Fazal et al., 1994). Losses up to $30 \%$ and $47 \%$ were caused by Alternaria brassicae in cauliflower (Brassica oleracea var botrytis) (Tamayo et al., 2001) and Indian mustard (Brassica juncea) (Chattopadhyay, 2008) respectively. Morphological characteristics of conidia and conidiophores and sometimes host plant association, provide the major taxonomic criteria for delimitation of fungal species (David, 1991). However, the classification of small spored species, including host-specific toxin producing fungi, has been particularly confused, because of the simple and convergent morphology of conidia and facultative parasitism, resulting in an ambiguous host range (Simmons, 1999). However, according to the study of Pattanamahakul and Strange (1999), the taxonomy of Alternaria on brassicas has been based principally on morphology and sometimes host plant association of each of the species occurring ( $A$. brassicicola, $A$. brassicae and $A$. raphani) has a distinct morphology considering the diversity of conidium shapes and sizes among Alternaria spp. All commercial cultivars of brassicas are susceptible to this pathogen (Tewari, 1991). Till now no resistance are found among the crucifers against Alternaria brassicae. Development of resistant cultivars requires knowledge of pathogen variation present in different regions where these crucifers are grown. Severity of Alternaria blight on Brassicas differs among seasons and regions as also between individual crops within a region. This may be due to existence of variability among isolates of Alternaria species. Many reports on the existence of morphological variability within the isolates of other Alternaria species have been reported by earlier workers (Verma and Saharan, 1994; Varma et al., 2006). Variability in the morphological characteristics in $A$. brassicae isolates of different regions of India have been reported (Meena et al., 2005; Kaur et al., 2007; Singh et al., 2007; Goyal et al., 2011).

Some researchers have worked on cultural variability in Alternaria species in respect of mycelial growth and sporulation (Ansari et al., 1989), media (Patni et al., 2005). Variability on the basis of morphology, sporulation, growth and other cultural characteristics also have been reported earlier (Kaur et al., 2007). Morphological and cultural variability among the oilseeds Brassica isolates of A. brassicae from different geographical regions of India were reported from across the rapeseed-mustard growing region of India (Goyal et al., 2011). However variability among the $A$. brassicae isolates from vegetable crop like Cauliflower is still missing.

The molecular approaches have been used increasingly in taxonomy and systematics of filamentous fungi including phytopathogens at the species and subspecies level (Benali et al., 2011). Variation in nuclear ribosomal DNA sequences among Alternaria species pathogenic to crucifers has recently been reported from $A$. brassicae, $A$. brassicicola (Schwein) Wiltshire, A. raphani J. W. Groves
\& Skolko and $A$. alternata (Fr.) Keissl. (Jasalavich et al., 1995).

The objective of this study was to evaluate isolates of A. brassicae collected from both crucifer crops cauliflower (vegetable) and mustard (oilseed) at morphological and cultural level and further relate at molecular level.

\section{MATERIALS AND METHODS}

Collection and maintenance of Alternaria brassicae isolates from black spot infected leaf samples

Alternaria brassicae isolates were obtained from black leaf spot infected leaf samples of both cauliflower and mustard (Table 1) collected during winter season in 2009 to 2011 from seven different regions of India namely Delhi, Uttar Pradesh, Rajasthan, Haryana, West Bengal, Tamil Nadu and Kerala. To obtain isolates from infected cauliflower and mustard leaves and other plant tissues, blighted leaf and stem pieces $(2 \mathrm{~mm})$ were surface sterilized with $0.1 \%$ Mercuric Chloride $\left(\mathrm{HgCl}_{2}\right)$ for one minute, rinsed in sterile water $3 x$ for 10 min and placed on Potato Dextrose Agar (PDA) plates. Fungal growth was observed after 5-7 days of incubation at $25^{\circ} \mathrm{C}$. A . brassicae isolates growing on the leaf/stem pieces were transferred onto other PDA plates until purification by single spore technique. These isolates were purified and preserved as PDA slants at $4^{\circ} \mathrm{C}$.

\section{Single spore isolation}

A total of 32 putative single spore Alternaria colonies were randomly picked from the lesions on infected plant parts under binocular microscope, and seeded onto the surface of water agar using tip of a sharp sterile inoculating needle. Inoculated plates were incubated on laboratory bench at room temperature (20$24^{\circ} \mathrm{C}$ ). Conidial germination on the plates was checked daily and upon germination, agar blocks bearing single germinated conidia were cut out and aseptically seeded on PDA plates. The plates were incubated for 14 days at room temperature and natural lighting conditions $\left(20-24^{\circ} \mathrm{C}\right.$ and $12-\mathrm{h}$ light). Plates of primary media were centrally inoculated with 2-mm diameter plugs taken from the edge of actively growing 4 day old cultures, and then incubated at $25^{\circ} \mathrm{C}$ after $72 \mathrm{~h}$, the colony diameters were measured and agar blocks were transferred to the fresh media. Spore yields were determined with a haemocytometer after $24 \mathrm{~h}$ of incubation on different media.

\section{Evaluation of morphological characters}

All the isolates were microscopically identified based on their morphology on PDA using light microscope (Carl Zeiss, Germany) and available literature (Ellis, 1971). For all isolates, morphological characteristics of the colony and sporulation apparatus were determined from single-spored colonies as described earlier. The nature of mycelia growth, shape of conidia was noted. The size and shape of conidia (length and width) was determined using ocular and stage micrometer. Numbers of septa were also recorded.

\section{Effect of different types of media type on growth and sporulation}

The objective of this experiment was to establish the suitable growth conditions for the in vitro growth and sporulation of Alternaria pathogen. Investigation was done on growth rate and conidia formation of the Alternaria pathogen. Seven types of media 
Table 1. Morphological and cultural characteristics of Alternaria brassicae isolates (32) collected from Cauliflower and Mustard grown in different states of India.

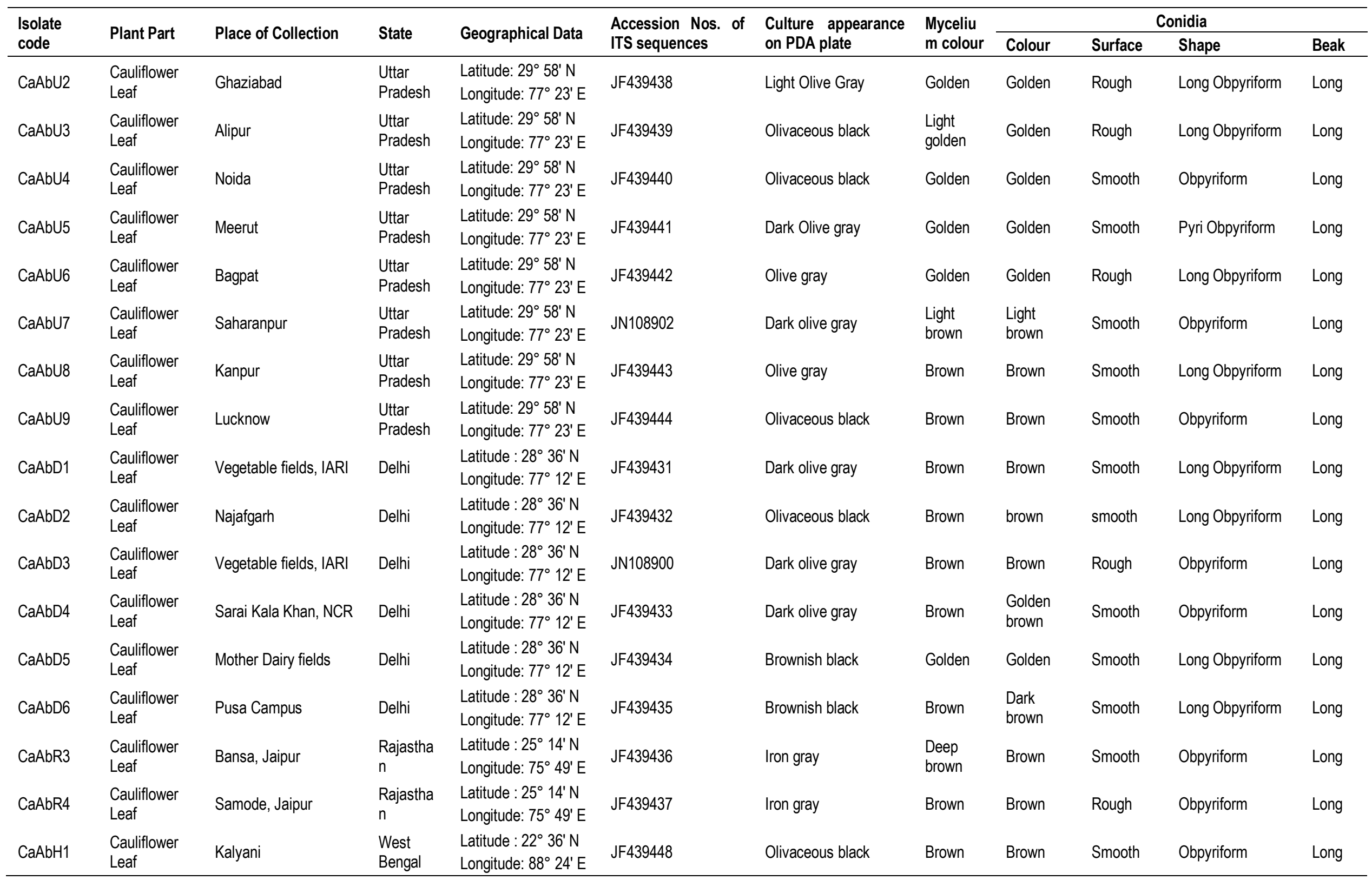


Table 1. Contd.

\begin{tabular}{|c|c|c|c|c|c|c|c|c|c|c|c|}
\hline CaAbK1 & $\begin{array}{l}\text { Cauliflower } \\
\text { Leaf }\end{array}$ & Hoogli & $\begin{array}{l}\text { West } \\
\text { Bengal }\end{array}$ & $\begin{array}{l}\text { Latitude : } 22^{\circ} 36^{\prime} \mathrm{N} \\
\text { Longitude: } 88^{\circ} 24^{\prime} \mathrm{E}\end{array}$ & JF439449 & Olive gray & Brown & Brown & Rough & Obpyriform & Long \\
\hline CaAbW1 & $\begin{array}{l}\text { Cauliflower } \\
\text { Leaf }\end{array}$ & Kolkata & $\begin{array}{l}\text { West } \\
\text { Bengal }\end{array}$ & $\begin{array}{l}\text { Latitude : } 22^{\circ} 36^{\prime} \mathrm{N} \\
\text { Longitude: } 88^{\circ} 24^{\prime} \mathrm{E}\end{array}$ & JF439450 & Dark olive gray & Brown & Brown & Smooth & Obpyriform & Long \\
\hline CaAbW2 & $\begin{array}{l}\text { Cauliflower } \\
\text { Leaf }\end{array}$ & Sonepat & Haryana & $\begin{array}{l}\text { Latitude : } 28^{\circ} 59^{\prime} \mathrm{N} \\
\text { Longitude: } 77^{\circ} 0^{\prime} \mathrm{E}\end{array}$ & JF439445 & Dark olive gray & Brown & Brown & Rough & Obpyriform & Long \\
\hline CaAbW3 & $\begin{array}{l}\text { Cauliflower } \\
\text { Leaf }\end{array}$ & Pallakkad & Kerala & $\begin{array}{l}\text { Latitude : } 10^{\circ} 00^{\prime} \mathrm{N} \\
\text { Longitude : } 76^{\circ} 25^{\prime} \mathrm{E}\end{array}$ & JF439446 & Black & Brown & Brown & Smooth & Obpyriform & Long \\
\hline CaAbT5 & $\begin{array}{l}\text { Cauliflower } \\
\text { Leaf }\end{array}$ & Coimbatore & $\begin{array}{l}\text { Tamil } \\
\text { Nadu }\end{array}$ & $\begin{array}{l}\text { Latitude : } 11^{\circ} 00^{\prime} \mathrm{N} \\
\text { Longitude : } 78^{\circ} 00^{\prime} \mathrm{E}\end{array}$ & JF439447 & Olivaceous black & Brown & Brown & smooth & Obpyriform & Long \\
\hline MAb1 & Mustard Leaf & IARI fields & Delhi & $\begin{array}{l}\text { Latitude : } 28^{\circ} 36^{\prime} \mathrm{N} \\
\text { Longitude: } 77^{\circ} 12^{\prime} \mathrm{E}\end{array}$ & JN108903 & Dark Olive gray & Brown & $\begin{array}{l}\text { Dark } \\
\text { brown }\end{array}$ & Smooth & Obpyriform & Long \\
\hline MAb2 & Mustard Leaf & IARI fields & Delhi & $\begin{array}{l}\text { Latitude : } 28^{\circ} 36^{\prime} \mathrm{N} \\
\text { Longitude: } 77^{\circ} 12^{\prime} \mathrm{E}\end{array}$ & JN108904 & Dark Olive gray & Brown & Brown & Smooth & Obpyriform & Long \\
\hline MAb3 & Mustard Leaf & IARI fields & Delhi & $\begin{array}{l}\text { Latitude : } 28^{\circ} 36^{\prime} \mathrm{N} \\
\text { Longitude: } 77^{\circ} 12^{\prime} \mathrm{E}\end{array}$ & JN108905 & Olivaceous black & Brown & $\begin{array}{l}\text { Dark } \\
\text { brown }\end{array}$ & Smooth & Obpyriform & Long \\
\hline MAb4 & Mustard Leaf & IARI fields & Delhi & $\begin{array}{l}\text { Latitude : } 28^{\circ} 36^{\prime} \mathrm{N} \\
\text { Longitude: } 77^{\circ} 12^{\prime} \mathrm{E}\end{array}$ & JN108906 & Olivaceous black & Brown & Brown & Smooth & Obpyriform & Long \\
\hline MAb5 & Mustard Leaf & IARI fields & Delhi & $\begin{array}{l}\text { Latitude : } 28^{\circ} 36^{\prime} \mathrm{N} \\
\text { Longitude: } 77^{\circ} 12^{\prime} \mathrm{E}\end{array}$ & JN108907 & Olivaceous black & Brown & Brown & Smooth & Obpyriform & Long \\
\hline MAb6 & Mustard Leaf & IARI fields & Delhi & $\begin{array}{l}\text { Latitude : } 28^{\circ} 36^{\prime} \mathrm{N} \\
\text { Longitude: } 77^{\circ} 12^{\prime} \mathrm{E}\end{array}$ & JN108908 & Olivaceous black & Brown & Brown & Smooth & Obpyriform & Long \\
\hline MAb7 & Mustard Leaf & IARI fields & Delhi & $\begin{array}{l}\text { Latitude : } 28^{\circ} 36^{\prime} \mathrm{N} \\
\text { Longitude: } 77^{\circ} 12^{\prime} \mathrm{E}\end{array}$ & JN108909 & Olivaceous black & Brown & Brown & Smooth & Obpyriform & Long \\
\hline MAb8 & Mustard Leaf & IARI fields & Delhi & $\begin{array}{l}\text { Latitude : } 28^{\circ} 36^{\prime} \mathrm{N} \\
\text { Longitude: } 77^{\circ} 12^{\prime} \mathrm{E}\end{array}$ & JN108910 & Olivaceous black & Brown & Brown & Smooth & Obpyriform & Long \\
\hline MAb10 & Mustard Leaf & Katyali & $\begin{array}{l}\text { Uttar } \\
\text { Pradesh }\end{array}$ & $\begin{array}{l}\text { Latitude: } 29^{\circ} 58^{\prime} \mathrm{N} \\
\text { Longitude: } 77^{\circ} 23^{\prime} \mathrm{E}\end{array}$ & JN108911 & Olivaceous black & Brown & Brown & Smooth & Obpyriform & Long \\
\hline MAb11 & Mustard Leaf & Katyali & $\begin{array}{l}\text { Uttar } \\
\text { Pradesh }\end{array}$ & $\begin{array}{l}\text { Latitude: } 29^{\circ} 58^{\prime} \mathrm{N} \\
\text { Longitude: } 77^{\circ} 23^{\prime} \mathrm{E}\end{array}$ & JN108912 & Olivaceous black & Brown & Brown & Smooth & Obpyriform & Long \\
\hline
\end{tabular}

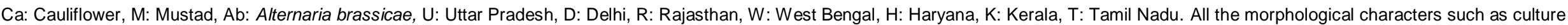

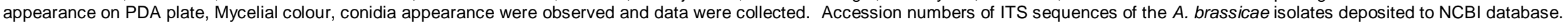


were tested to determine their effect on growth and sporulation of the pathogen. These were potato dextrose agar (PDA), Cauliflower agar media (CAM), Carrot Potato Agar (CPA), Oat Meal Agar (OMA), Czapex Dox Agar (CDA), V8-Juice Agar (VJA) and Corn Meal Agar (CMA). The different media served the purposes of growing of cultures, cleaning of cultures and sporulation of cultures.

Growth media for Alternaria species was i) Potato dextrose agar (PDA) made of Dextrose $(20 \mathrm{~g})$, agar $(15 \mathrm{~g})$ and Potatoes infusion from $200 \mathrm{~g}$ in $1000 \mathrm{ml}$ water, ii) Cauliflower Agar Media (CAM) made of Dextrose $(20 \mathrm{~g})$, agar $(15 \mathrm{~g})$ and Cauliflower infusion from $200 \mathrm{~g}$ in $1000 \mathrm{ml}$ water, iii) Carrot Potato agar (CPA) $24 \mathrm{~g}$ in 1000 $\mathrm{ml}$ distilled water, iv)Oat Meal Agar (OMA), $38 \mathrm{~g}$ in $1000 \mathrm{ml}$ distilled water, v) Czapex Dox Agar (CDA) $49 \mathrm{~g}$ in $1000 \mathrm{ml}$ distilled water, vi) V8 Juice Agar (VJA) $44.3 \mathrm{~g}$ in $1000 \mathrm{ml}$ distilled water and vii) Corn Meal Agar (CMA) $17 \mathrm{~g}$ in $1000 \mathrm{ml}$ distilled water. All synthesized media were of Himedia. The agar plates were autoclaved at $121^{\circ} \mathrm{C}$ for $15 \mathrm{~min}$ and approximately $20 \mathrm{ml}$ were dispensed into sterile 90 $\mathrm{mm}$ plastic Petri dishes to form a layer of $2 \mathrm{~mm}$ deep. The media was inoculated using a uniform culture plug of $4 \mathrm{~mm}$ in diameter obtained from 14-day-old culture plates and placed in the centre of each dish. The plates were incubated at room temperature. The experiment was arranged in a completely randomized design with 3 replicates. Fungal growths (Radial growth in $\mathrm{cm}$ ) of different isolates were studied. Measurements on radial colony diameter were taken on 7th day after inoculation whereby six plates were sampled each time for each media treatment.

\section{Measurement of fungal sporulation}

To determine conidial concentration of each isolates, cultures grown in the seven different media plates were considered. Ten milliliter $(10 \mathrm{ml})$ of sterile distilled water was added to culture plate and using a sterile glass slide, the culture surface was gently scrapped to make a conidial suspension. Conidial concentration was determined using a haemocytometer.

\section{Pathogencity testing of $\boldsymbol{A}$. brassicae isolates}

Twenty-two A. brassicae isolates from Cauliflower were tested for symptom production on a susceptible cultivar of Cauliflower viz., DC-23000. Similarly ten $A$. brassicae isolates from Mustard were tested on a susceptible variety of mustard viz., Pusa Jagganath. The seeds of cauliflower were sown in nursery beds during October, 2009-2010 and 2010-2011 seasons. Cauliflower Seedlings were transplanted after two weeks in fields with a spacing of $30 \mathrm{~cm}$ x $40 \mathrm{~cm}$. Similarly mustard seeds were sown on fields. After 60 days leaves from both the cauliflower and mustard plant were taken for the detached leaf inoculation method. Test Leaves were properly washed under running tap water and then surface wiped off with $70 \%$ alcohol and 2 microlitres of $4 \times 10^{4}$ spores $\mathrm{ml}^{-1}$ spores were inoculated with a fine needle (Dispovan, $2.5 \mathrm{ml}$ ) while sterile distilled water was applied on control. The leaves were placed inside moist chambers in green house conditions and were observed for appearance of disease symptoms on 7 day after inoculation. Experiments were conducted in completely randomized design (CRD). Each treatment consisted of three replicates. Symptoms observed were ranked as minus (-) for no symptom and plus $(+)$ for black leaf spot with yellow halos on inoculated leaves. Appearance of symptom again divided into three groups viz., black spot with diameter $0.2-0.5 \mathrm{~cm}$ ranked as single plus $(+)$, spot with diameter $0.6-1.0 \mathrm{~cm}$ ranked as double plus $(++)$ and spot diameter more than $1 \mathrm{~cm}$ were ranked as three plus sign $(+++)$.

\section{DNA extraction and purification}

All the $32 A$. brassicae (22 from cauliflower and 10 from mustard) isolates were grown on Potato Dextrose Broth (PDB) medium in
$100 \mathrm{ml}$ capacity conical flask for 7 days at $28^{\circ} \mathrm{C}$. Mycelial mats were harvested by Whatman No.1 filter papers and lyophilized. DNA was isolated according to a modified Cetyl trimethyl ammonium bromide (CTAB) method (Doyle and Doyle, 1990). Around $300 \mathrm{mg}$ of lyophilized fungal material was ground in liquid nitrogen, dispersed in $800 \mu \mathrm{l}$ of $2 \% \mathrm{CTAB}$ extraction buffer at $65^{\circ} \mathrm{C}$ in water bath for 30 min. An equal volume of Chloroform: isoamyl alcohol $(24: 1, \mathrm{v} / \mathrm{v})$ was added, mixed well and centrifuged (4000 rpm, 10min). The upper aqueous phase was transferred to a fresh tube. Nucleic acids were precipitated by adding 0.6 volume of ice cold isopropanol, and collected by centrifugation (14000 rpm for $30 \mathrm{~min}$ ). Pellet was washed twice with $70 \%$ ethanol and then air dried by putting the tube face down on a paper towel. Then pellet were solubilized in $200 \mu \mathrm{l}$ TE buffer $(10 \mathrm{mM}$ Tris-HCl, $1 \mathrm{mM}$ EDTA, pH- 8.0). DNA extracts were then purified by treating with $10 \mathrm{U}$ of DNase- free RNase (Biomatrix Corp) for one hour at $37^{\circ} \mathrm{C}$. RNase was removed by Phenol: Chloroform: Isoamyl alcohol (25:24:1) extraction step. DNA was treated with $3 \mathrm{M}$ Sodium Acetate and ethanol precipitated, centrifuged, dried and dissolved in an appropriate volume of TE buffer.

\section{Internal transcribed spacer (ITS) region analysis}

Thirty two $A$. brassicae isolates were analyzed by amplifying the regions of the rDNA repeat from the 3 'end of the $18 \mathrm{~s}$ and the $5^{\prime}$ end of the 28s gene using PCR conditions with the two universal primers, ITS1-3' TCC GTA GGT GAA CCT GCG G 5' and ITS4-3' TCC TCC GCT TAT TGA TAT GC 5' which were synthesized on the basis of conserved regions of the eukaryotic rRNA gene (White et al., 1990; Jasalavich et al., 1995). The PCR- amplification reactions were performed in a $25 \mu \mathrm{l}$ mixture containing $50 \mathrm{mM} \mathrm{KCl}$, $20 \mathrm{mM}$ Tris $\mathrm{HCl}(\mathrm{pH} 8.0), 2.0 \mathrm{mM} \mathrm{MgCl}, 20 \mu \mathrm{M}$ of each of the four deoxynucleotide triphosphates, $20 \mathrm{pmol}$ of each primer, $50 \mathrm{ng} / \mu \mathrm{l}$ of template and $2.5 \mathrm{U}$ of Taq polymerase. These reactions were subjected to an initial denaturation hot start at $94^{\circ} \mathrm{C}$ for $4 \mathrm{~min}$, followed by 40 cycles of denaturation at $94^{\circ} \mathrm{C}$ for $35 \mathrm{~s}$, primer annealing at $60^{\circ} \mathrm{C}$ for $1 \mathrm{~min} 30 \mathrm{~s}$ and primer extension at $72^{\circ} \mathrm{C}$ for 3 min and a final extension for $10 \mathrm{~min}$ at $72^{\circ} \mathrm{C}$ in a thermal cycler. Aliquots $(4 \mu \mathrm{l})$ of the amplified products were analysed by electrophoresis in $1.5 \%(\mathrm{wt} / \mathrm{vol})$ agarose gel in $1 \mathrm{X}$ TAE buffer $(40 \mathrm{mM}$ Tris, $20 \mathrm{mM}$ acetic acid, $1 \mathrm{mM}$ EDTA [pH8]), stained with ethidium bromide $(1 \mu \mathrm{g} / \mathrm{ml})$ and electrophoresis was carried out at 70 volts for $2 \mathrm{~h}$ in TAE buffer. The molecular marker was $100 \mathrm{bp}$ ladder (Biomatrix Co. Ltd.). The desired bands were cut from the gel with minimum quantity of gel portion and the amplified PCR product was eluted using QIAGEN DNA gel extraction kit.

\section{Nucleotide sequencing and in silico analysis}

The sequencing of the PCR product was carried out in automated Sequencer at Xcelris Lab., Bangalore, India. Related sequences were searched for homology using BLAST bioinformatic search tool available at the Gen-Bank database (http://www.ncbi.nlm.nih.gov/blast/) (Altschul et al., 1997). Sequences used for comparison were obtained from NCBI database (http://www.ncbi.nlm.nih.gov) and the details are given in the results.

The multiple sequence alignment and pair wise alignment were performed using the Clustral W algorithm in Bioedit (Hall, 1999) and Phylogenetic analysis was done using MEGA5.0 (Tamura et al., 2011) software. To assess the possible phylogenetic relationship neighborhood-joining bootstrap tree was created using CLUSTAL W 1.6 matrix by the CLUSTAL X programme ver. 1.81 (Thompson et al., 1997). The ITS sequences were submitted to GenBank. Sequences used for comparison were obtained from NCBI database (http://www.ncbi.nlm.nih.gov) and the details are given in the results. 


\section{Statistical analysis}

Averages of colony diameter on each media plates and number of conidial $\mathrm{ml}$ for each isolates were taken for subsequent data analysis. Analysis of variance and separation of means to determine differences in growth rates on media types was analyzed by performing two-way ANOVA using statistical software PRISM version 3.0 at $p<0.0001$. Similarly the conidial characters were also statistically analyzed at $p<0.05$ by performing one way ANOVA and least significant difference was calculated by student's t-test.

\section{RESULTS}

\section{Morphological characterization}

Differences in rates of linear growth and colour of the colony were observed among all 32 isolates of $A$. brassicae (Table 1; Figure 1) obtained from the infected Cauliflower and Mustard leaves. The color of the colonies and the conidia grown on PDA showed little variation. The color of the $A$. brassicae isolates varies between light olive gray to olivaceous black. The mycelia colour varies between brown and golden. The conidia characteristics were also similar to each other among the isolates viz., conidia color was golden or brown with mostly smooth surface. Most of the conidia were long obpyriform in shape with long beak.

The 32 single-spore cultures of $A$. brassicae showed significant $(P<0.05)$ morphological variability in respect of conidia length, conidia width and number of septa (Table 2; Figure 1). Average conidial length, which varied from 37.88 to $57.65 \mu \mathrm{m}$, was highest in West Bengal cauliflower isolate (CaAbW1) that is, $57.65 \mu \mathrm{m}$ and lowest in Delhi mustard isolate (MAb2) that is, $37.88 \mu \mathrm{m}$. Average conidial width, which varied from 6 to $9.5 \mu \mathrm{m}$, was highest in West Bengal cauliflower (CaAbW2) isolates that is, $9.5 \mu \mathrm{m}$ and lowest in Delhi cauliflower isolate $(\mathrm{CaAbD} 1)$ that is, $6 \mu \mathrm{m}$. The average number of transverse septa, which varied from 2.33 to 6 , was highest in Delhi cauliflower (CaAbD4) isolates that is, 6 and lowest in Delhi mustard isolate (MAb6) that is, 2.33.

Finally it was revealed that the smallest size of conidia and lowest number of septa was seen in Delhi isolate (MAb2, CaAbD1 and MAb6 isolates respectively). Microscopic examination of conidia at 40X magnification revealed variability in conidia size and could be categorized into two groups, that is, small $(<47 \mu \mathrm{m})$ and long $(>47 \mu \mathrm{m})$ but not according to their geographical origin. The small group included isolates from Delhi (CaAbD1, CaAbD2, CaAbD5 and CaAbD6, MAb2, MAb3, MAb4), Uttar Pradesh (CaAbU2, CaAbU3, CaAbU4, CaAbU5, CaAbU9) and Rajasthan (CaAbR3, CaAbR4) while long group included isolates from West Bengal (CaAbW1, CaAbW2, CaAbW3), Uttar Pradesh (CaAbU6, CaAbU7, CaAbU8,MAb10, MAb11), Delhi (CaAbD3, CaAbD4, MAb1, MAb5, MAb6, MAb7, MAb8), Haryana (CaAbH1), Kerala (CaAbK1) and Tamil Nadu (CaAbT5) states.

\section{Effect of different media on radial growth}

Mycelial growth and sporulation varied among the different isolates in different synthetic media. According to the average of radial growth of different isolates on different media, Potato Dextrose Agar and Cauliflower Agar was optimum for all the cultures. Radial growth on the $7^{\text {th }}$ day of 14 isolates [Uttar Pradesh (CaAbU3, CaAbU4, CaAbU7), Delhi (CaAbD1, CaAbD2, CaAbD3, CaAbD4, MAb6), Rajasthan (CaAbR3, CaAbR4), Haryana (CaAbH1), Kerala (CaAbK1), West Bengal (CaAbW1), Tamil Nadu (CaAbT5)] were higher on PDA medium $(>8 \mathrm{~cm})$. Among them Uttar Pradesh (CaAbU3) and Delhi $(\mathrm{CaAbD} 3)$ showed highest growth $(8.87 \mathrm{~cm})$ while Uttar Pradesh (CaAbU8) grew the least $(4.86 \mathrm{~cm})$. On Cauliflower agar media, Carrot Potato and Oat Meal Agar media highest growth were observed in Haryana $(\mathrm{CaAbH} 1): 7.60 \mathrm{~cm}$, Haryana $(\mathrm{CaAbH} 1)$ and Rajasthan (CaAbR4): $7.47 \mathrm{~cm}$ and Delhi (CaAbD4): $7.37 \mathrm{~cm}$ respectively whereas least growth was found in Delhi (MaAb5):5.43 cm, Uttar Pradesh (CaAbU2):5.77 and Tamil Nadu (CaAbT5):5.17 cm respectively. Similarly in Czapex-Dox agar media highest growth was found in Delhi (CaAbD1):6.93 cm and least growth in Haryana $(\mathrm{CaAbH} 1): 4.83 \mathrm{~cm}$. Rest two media viz., V8 juice agar and Corn meal agar showed the lowest growth ranging $(2.93-5.13 \mathrm{~cm})$ and $(2.13-4.43 \mathrm{~cm})$ respectively.

A dendrogram (Figure 2) was constructed based on the data for mycelial growth of $A$. brassicae isolates on the $7^{\text {th }}$ day at different nutrient media at a temperature of $25^{\circ} \mathrm{C}$, from the similarity coefficient by using Unweighted Pair Group Method with Average Means (UPGMA). The dendrogram identified two major clusters with $82 \%$ similarity. One cluster (group I) comprised of 16 isolates from Uttar Pradesh (CaAbU2, MAb11), Delhi (CaAbD3, CaAbD5, CaAbD6, MAb2, MAb3, MAb4, MAb6, MAb8), Tamil Nadu (CaAbT5), Kerala (CaAbK1), West Bengal (CaAbW1, CaAbW2, CaAbW3) and Rajasthan (CaAbR3) while another cluster (group II) comprised of remaining 16 isolates of which one Delhi isolate $(\mathrm{CaAbD} 4)$ was separated from the rest fifteen isolates at $86 \%$ similarity level. The fifteen isolates of group II shares $100 \%$ similarity among the isolates viz., Uttar Pradesh isolates (CaAbU3, CaAbU4, CaAbU5, CaAbU6, CaAbU7, CaAbU8, CaAbU9 and MAb10), Delhi isolates (CaAbD1, CaAbD2, MAb1, MAb5, MAb7), Haryana isolate $(\mathrm{CaAbH} 1)$ and Rajasthan isolate $(\mathrm{CaAbR} 4)$.

\section{Effect of different media on sporulation}

Sporulation of each $A$. brassicae isolates on the $7^{\text {th }}$ day on different media was almost similar. The lowest sporulation was observed for the isolates of Uttar Pradesh (CaAbU2, CaAbU3), Delhi (CaAbD3) and Haryana $(\mathrm{CaAbH} 1)$ which was in a range 2.67-6.33 $\times 10^{4} / \mathrm{ml}$. Moderately sporulating within a range of $7-10 \times 10^{4} / \mathrm{ml}$ were 


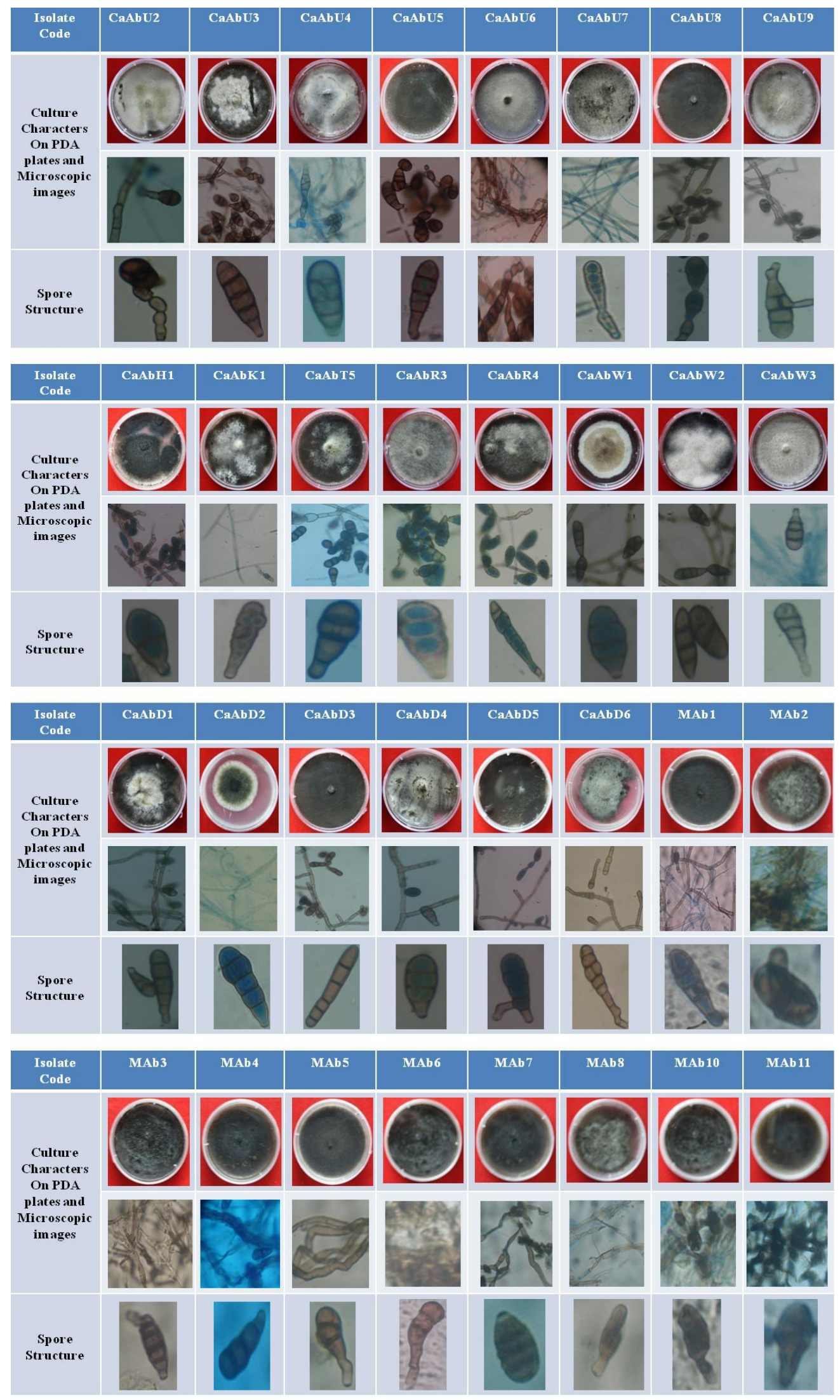

Figure 1. Spore morphology and cultural characters on PDA plates and microscopic images of Alternaria brassicae isolates. 
Table 2. Conidial size and septation of Alternaria brassicae isolates.

\begin{tabular}{|c|c|c|c|}
\hline Isolate & Average conidial length $(\mu \mathrm{m})$ & Average conidial breadth $(\mu \mathrm{m})$ & Average Number of Transverse septa \\
\hline CaAbU2 & 40.32 & 7.50 & 5.33 \\
\hline CaAbU3 & 38.43 & 7.90 & 5.67 \\
\hline CaAbU4 & 38.22 & 6.20 & 4.00 \\
\hline CaAbU5 & 45.54 & 7.20 & 4.67 \\
\hline CaAbU6 & 50.43 & 8.50 & 5.00 \\
\hline CaAbU7 & 53.28 & 8.60 & 3.67 \\
\hline CaAbU8 & 49.50 & 7.40 & 4.33 \\
\hline CaAbU9 & 38.48 & 6.10 & 4.67 \\
\hline CaAbD1 & 42.16 & 6.00 & 4.33 \\
\hline CaAbD2 & 44.36 & 6.80 & 4.00 \\
\hline CaAbD3 & 48.64 & 7.40 & 5.00 \\
\hline CaAbD4 & 47.98 & 7.10 & 6.00 \\
\hline CaAbD5 & 38.98 & 6.40 & 5.00 \\
\hline CaAbD6 & 40.08 & 7.20 & 3.67 \\
\hline CaAbR3 & 42.04 & 7.80 & 4.33 \\
\hline CaAbR4 & 46.87 & 8.40 & 5.67 \\
\hline $\mathrm{CaAbH} 1$ & 48.76 & 8.60 & 3.67 \\
\hline CaAbK1 & 48.88 & 8.40 & 4.00 \\
\hline CaAbW1 & 57.65 & 9.40 & 4.33 \\
\hline CaAbW2 & 52.11 & 9.50 & 4.67 \\
\hline CaAbW3 & 48.99 & 8.70 & 5.00 \\
\hline CaAbT5 & 54.77 & 9.60 & 5.00 \\
\hline MAb1 & 56.39 & 8.60 & 5.00 \\
\hline MAb2 & 37.88 & 7.50 & 2.67 \\
\hline MAb3 & 43.35 & 8.40 & 2.67 \\
\hline MAb4 & 44.99 & 8.30 & 4.67 \\
\hline MAb5 & 50.48 & 8.80 & 2.67 \\
\hline MAb6 & 52.62 & 8.40 & 2.33 \\
\hline MAb7 & 53.36 & 8.50 & 4.00 \\
\hline MAb8 & 47.56 & 7.90 & 2.33 \\
\hline MAb10 & 48.87 & 8.10 & 2.67 \\
\hline MAb11 & 56.43 & 8.60 & 4.67 \\
\hline LSD (0.05) & 2.08 & 0.34 & 0.36 \\
\hline CV (\%) & 12.48 & 12.12 & 23.65 \\
\hline
\end{tabular}

The size and shape of conidia (length and width) was determined using ocular and stage micrometer. Numbers of septa were also recorded.

seen for the isolates Rajasthan (CaAbR3, CaAbR4), West Bengal (CaAbW1), Kerala (CaAbK1), and Uttar Pradesh (CaAbU6, CaAbU7). Rest of the isolates were highly sporulating within a range of $12.33-50 \times 10^{4} / \mathrm{ml}$. Tamil Nadu isolate (CaAbT5) was found to be the highest sporulating with $50 \times 10^{4} / \mathrm{ml}$. Similar observations were found in all nutrient media.

Another dendrogram (Figure 3) was constructed based on the $7^{\text {th }}$ day for sporulation of $A$. brassicae isolates in the same way as for mycelial growth. This dendrogram produced two major clusters with $15 \%$ similarity. One cluster (group I) comprised of four isolates from Uttar Pradesh (CaAbU2, CaAbU3), Delhi (CaAbD3) and Haryana $(\mathrm{CaAbH} 1)$. This group is also the least sporulating group with less than $6 \times 10^{4} / \mathrm{ml}$ sporulation. Another cluster (group II) comprised of remaining twenty eight isolates which was further sub-clustered. Among the subclusters one comprised of twenty two isolates which were highly sporulating $\left(>10 \times 10^{4} / \mathrm{ml}\right)$. This sub cluster include Delhi isolates (CaAbD1, CaAbD2, CaAbD4, CaAbD5, CaAbD6, MAb1, MAb2, MAb3, MAb4, MAb5, MAb6, MAb7, MAb8), Uttar Pradesh isolates (MAb10, MAb11, CaAbU4, CaAbU5, CaAbU8, CaAbU9), Tamil Nadu isolates (CaAbT5), West Bengal (CaAbW2, CaAbW3). Another two sub-clusters comprised of isolates from Rajasthan (CaAbR3, CaAbR4), West Bengal (CaAbW1), Kerala (CaAbK1) and Uttar Pradesh (CaAbU6, CaAbU7).

Cluster analysis also revealed cultural variability among thirty two $A$. brassicae isolates and found a close relationship among Delhi and Uttar Pradesh isolates in respect of 


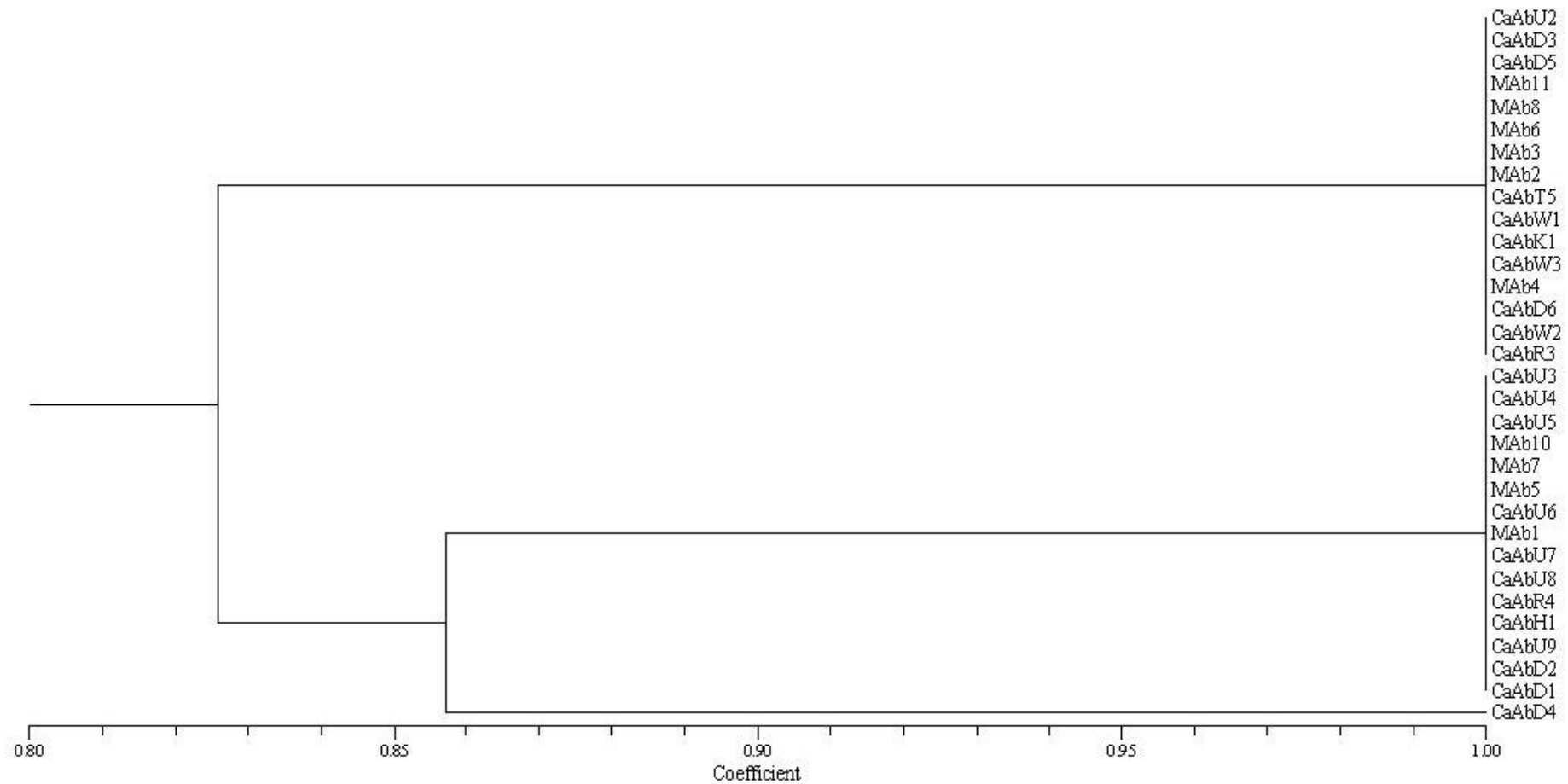

Figure 2. Dendrogram showing cultural variability in mycelial growth of 32 Alternaria brassicae isolates at different nutrient media.

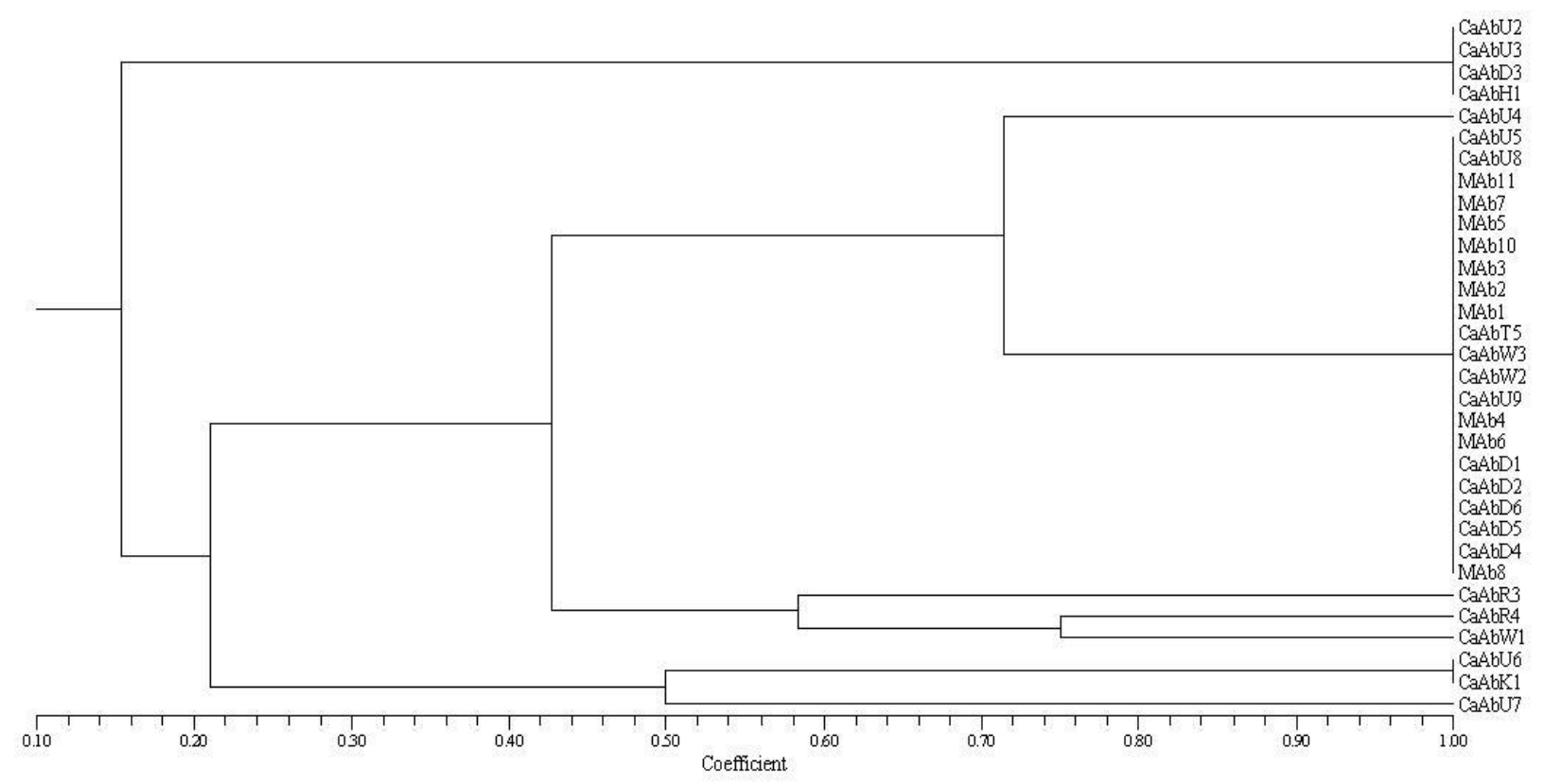

Figure 3. Dendrogram showing cultural variability in sporulation of 32 Alternaria brassicae isolates at different nutrient media.

mycelial growth and sporulation on different nutrient media.

\section{Pathogencity}

All the $A$. brassicae isolates both from cauliflower and mustard were found to be pathogenic in nature (Table 3).
Among the cauliflower isolates CaAbT5 from Tamil Nadu, CaAbD5 from Delhi and CaAbU8 from Uttar Pradesh were found to be highly pathogenic as the spots produced by them were $>1 \mathrm{~cm}$ in diameter. Cauliflower isolates CaAbU2, CaAbU3, CaAbU4, CaAbU6, CaAbU7 (Uttar Pradesh), CaAbD3 (Delhi), CaAbR3, CaAbR4 (Rajasthan), CaAbH1 (Haryana), CaAbK1 (Kerala), 
Table 3. Pathogenicity testing of $A$. brassicae isolates on the respective hosts cauliflower and mustard.

\begin{tabular}{lllllll}
\hline $\begin{array}{l}\text { Cauliflower } \\
\text { brassicae isolate }\end{array}$ & $\boldsymbol{A}$. & $\begin{array}{l}\text { Cauliflower } \\
\text { cultivar: DC-23000 }\end{array}$ & $\begin{array}{l}\text { Cauliflower } \\
\text { brassicae isolates }\end{array}$ & $\begin{array}{l}\text { A. } \\
\text { Cauliflower } \\
\text { cultivar: DC-23000 }\end{array}$ & $\begin{array}{l}\text { Mustard } \\
\text { brassicae isolates }\end{array}$ & $\begin{array}{l}\text { Mustard cultivar: } \\
\text { Pusa Jagganath }\end{array}$ \\
\hline CaAbU2 & + & CaAbD4 & ++ & MAb1 & ++ \\
CaAbU3 & + & CaAbD5 & +++ & MAb2 & ++ \\
CaAbU4 & + & CaAbD6 & ++ & MAb3 & ++ \\
CaAbU5 & ++ & CaAbR3 & + & MAb4 & ++ \\
CaAbU6 & + & CaAbR4 & + & MAb5 & ++ \\
CaAbU7 & + & CaAbH1 & + & MAb6 & ++ \\
CaAbU8 & +++ & CaAbK1 & + & MAb7 & ++ \\
CaAbU9 & ++ & CaAbW1 & + & MAb8 & ++ \\
CaAbD1 & ++ & CaAbW2 & ++ & MAb10 & ++ \\
CaAbD2 & ++ & CaAbW3 & ++ & MAb11 & ++ \\
CaAbD3 & + & CaAbT5 & +++ & & +
\end{tabular}

Symptoms observed were ranked as minus (-) for no symptom and plus (+) for black leaf spot with yellow halos on inoculated leaves. Appearance of symptom again divided into three groups viz., black spot with diameter $0.2-0.5 \mathrm{~cm}$ ranked as single plus $(+)$, spot with diameter $0.6-1.0 \mathrm{~cm}$ ranked as double plus $(++)$ and spot diameter more than $1 \mathrm{~cm}$ were ranked as three plus sign $(+++)$.

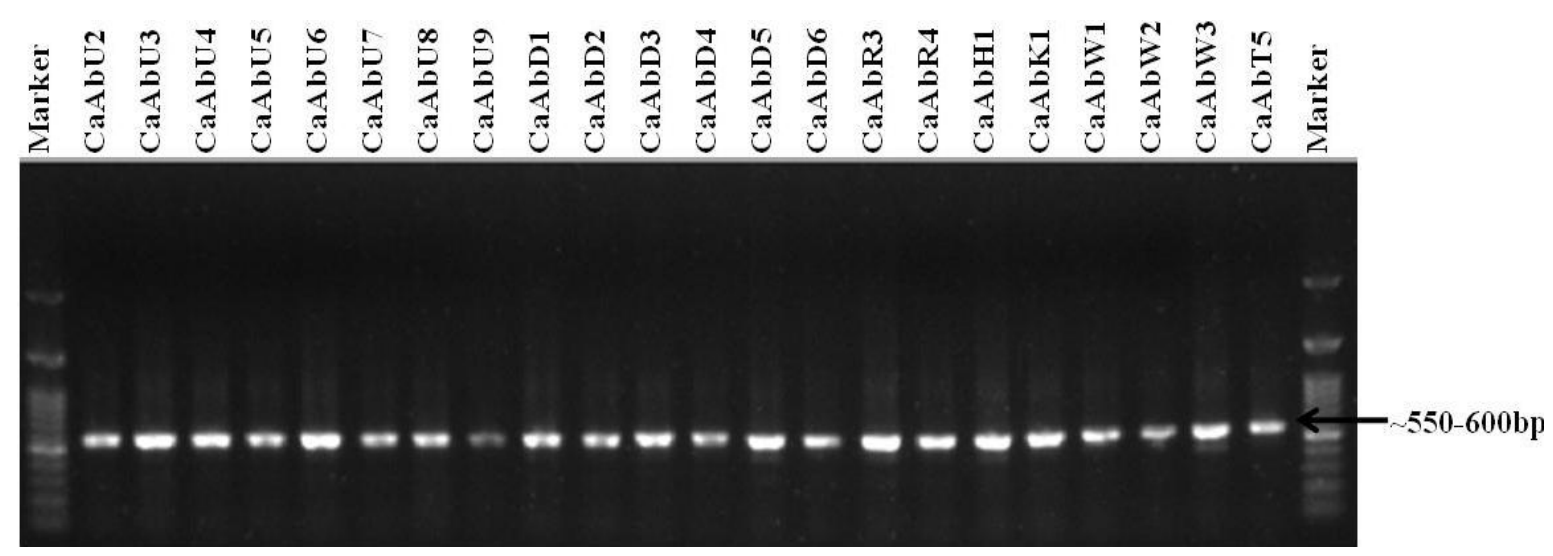

Figure 4. Amplification of the internal transcribed spacer region of the twenty two A.brassicae isolates collected from the infected cauliflower host from different part of India with the universal primer ITS1 and ITS4. Lane M: 100 bp ladder (GeneDirex RTU, Biochem Life Science, India).

CaAbW1 (West Bengal) were found least pathogenic as the symptoms of black spot produced were $0.2-0.5 \mathrm{~cm}$ in diameter. Isolates CaAbU5, CaAbU9, MAb10, MAb11 (Uttar Pradesh), CaAbD1, CaAbD2, CaAbD4, CaAbD6, MAb1, MAb2, MAb3, MAb4, MAb5, MAb6, MAb7, MAb8 (Delhi), CaAbW2, CaAbW3 (West Bengal) were found moderately pathogenic producing dark spots of size $0.6-1$ $\mathrm{cm}$.

\section{ITS analysis}

DNA was successfully extracted from the fungal isolates using CTAB method and yielded the PCR products of amplicons of $\sim 550$ to $600 \mathrm{bp}$. Preliminary fingerprinting of the 32 isolates using internal transcriber spacer primers ITS1- 5'TCC GTA GGT GAA CCT GCG 3' and ITS4-5' TCC TCC GCT TAT TGA TAT GC 3' confirmed that these isolates to be of Alternaria species (Figures 4 and
5). Analysis of the ITS regions revealed $90-100 \%$ identity among the thirty two isolates in the $A$. brassicae species group. All the ITS sequences were submitted to NCBI database (Table 1). The evolutionary history was inferred using the Neighbor-Joining method (Saitou and Nei, 1987). The optimal tree with the sum of branch length = 0.20085009 is shown. The percentage of replicate trees in which the associated taxa clustered together in the bootstrap test (1000 replicates) was shown next to the branches (Felsenstein, 1985). The evolutionary distances were computed using the Maximum Composite Likelihood method (Tamura et al., 2004) and are in the units of the number of base substitutions per site. The analysis involved 37 nucleotide sequences. Codon positions included were $1 s t+2 n d+3 r d+N o n c o d i n g$. All positions containing gaps and missing data were eliminated. There were a total of 513 positions in the final dataset. Evolutionary analyses were conducted in MEGA5 (Tamura 


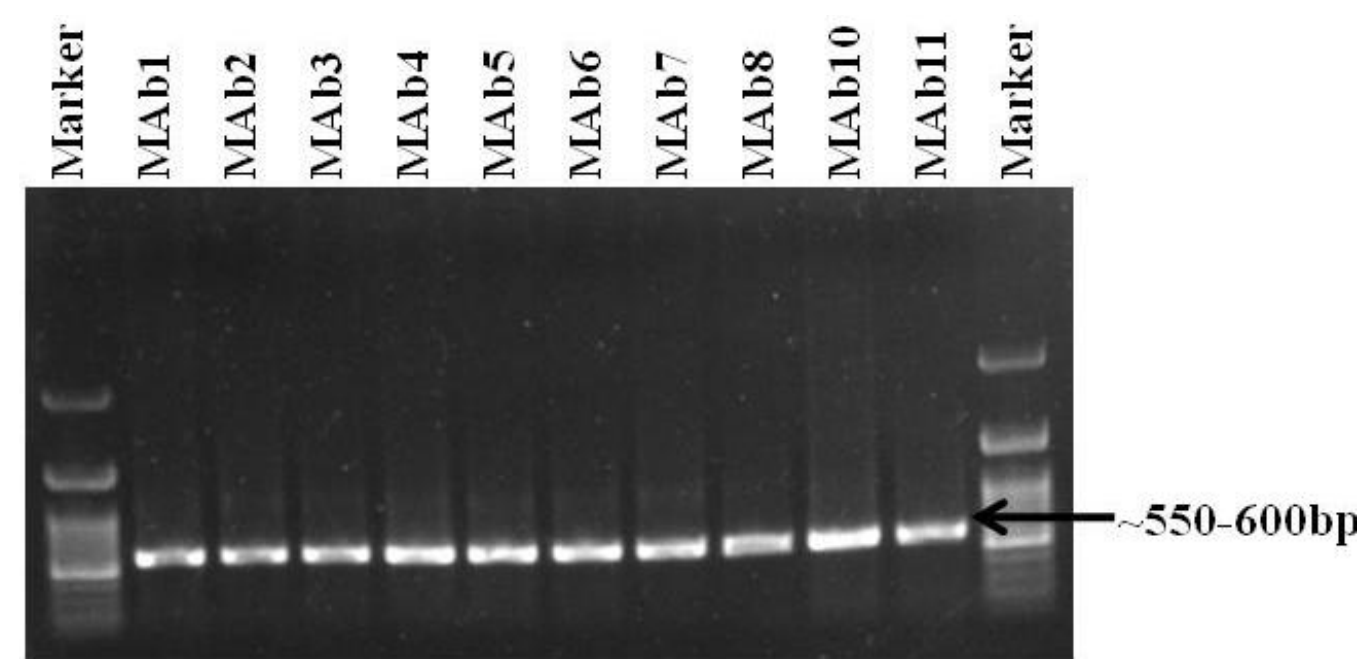

Figure 5. Amplification of the internal transcribed spacer region of the ten A.brassicae isolates collected from the infected cauliflower host from different part of India with the universal primer ITS1 and ITS4. Lane M: 100bp ladder (Gene Direx RTU, Biochem Life Science, India).

et al., 2011).

The phylogenetic tree (Figure 6) formed three distinct clusters of the $A$. brassicae isolates but there are not of much difference. First cluster comprises of only one isolate that is $\mathrm{CaAbD2}$, second group was formed constituting only two isolates of Rajasthan origin and cauliflower as source plant of isolation viz., CaAbR3 and CaAbR4 which are $99 \%$ similar to each other. The third group containing the rest of all isolates having $>56 \%$ similarities with each other. When some other accessions of $A$. brassicae were considered from NCBI it showed a close relationship with the isolates in the present study.

\section{DISCUSSION}

In a recent report Goyal et al. (2011) reported variation in conidial morphology, mycelial growth, sporulation of thirteen isolates of $A$. brassicae collected from different geographical zones were dependant on temperature and geographical origin. Similarly, variability in the morphological characteristics in $A$. brassicae isolates of different regions of India have been reported (Meena et al., 2005; Kaur et al., 2007; Singh et al., 2007). Some researchers have worked on cultural variability in Alternaria species in respect of mycelial growth and sporulation (Ansari et al., 1989; Patni et al., 2005; Kaur et al., 2007). Cauliflower and mustard are winter crops and are affected by $A$. brassicae. This present study was to understand the variability among the isolates infecting both the crops grown in different states of India on basis of morphology, cultural, pathogenic and molecular level. Significant variation in growth, sporulation and conidial morphology of $A$. brassicae isolates were found on different nutrient media irrespective of crop and geographical states. All the isolates were found pathogenic in nature against their respective host.
Due to the systematic and taxonomic usefulness the ITS region has been used in classifying fungi (Chillali et al., 1998) as it is suitable size for PCR amplification, restriction analysis and sequencing procedures, and because ITS regions are variable among species as well (Jung et al., 2002). Molecular relationships amongst Alternaria species based on nuclear ribosomal DNA and hostspecific toxins (Kusaba and Tsuge, 1994, 1995) or with other related fungi have been analyzed (Pryor and Gilbertson, 2002; Chou and Wu, 2002). Variation in nuclear ribosomal DNA sequences among Alternaria species pathogenic to crucifers has been reported from one isolate each of $A$. brassicae, $A$. brassicicola, A. raphani and $A$. alternata (Jasalavich et al., 1995). BLAST analysis of the internal transcribed spacer region of all thirty two $A$. brassicae isolates in this study showed high similarity among the isolates with $A$. brassicae of the NCBI database.

All the thirty two isolates of Alternaria brassicae though different at cultural and morphological level were found to be pathogenic in nature. Irrespective of the host and geographical origin the $A$. brassicae isolates are dispersed in the whole country sharing a single gene pool.

\section{ACKNOWLEDGEMENTS}

This study has been carried out with financial support from the Indian Council of Agricultural Research under the project Outreach programme on Diagnosis and management of leaf spot diseases of field and horticultural crops. The authors are grateful to Director, Indian Agricultural Research Institute, Director Indian Institute of Horticultural Institute, Bengaluru, and Head, Plant Pathology IARI for providing necessary facilities for the research. 


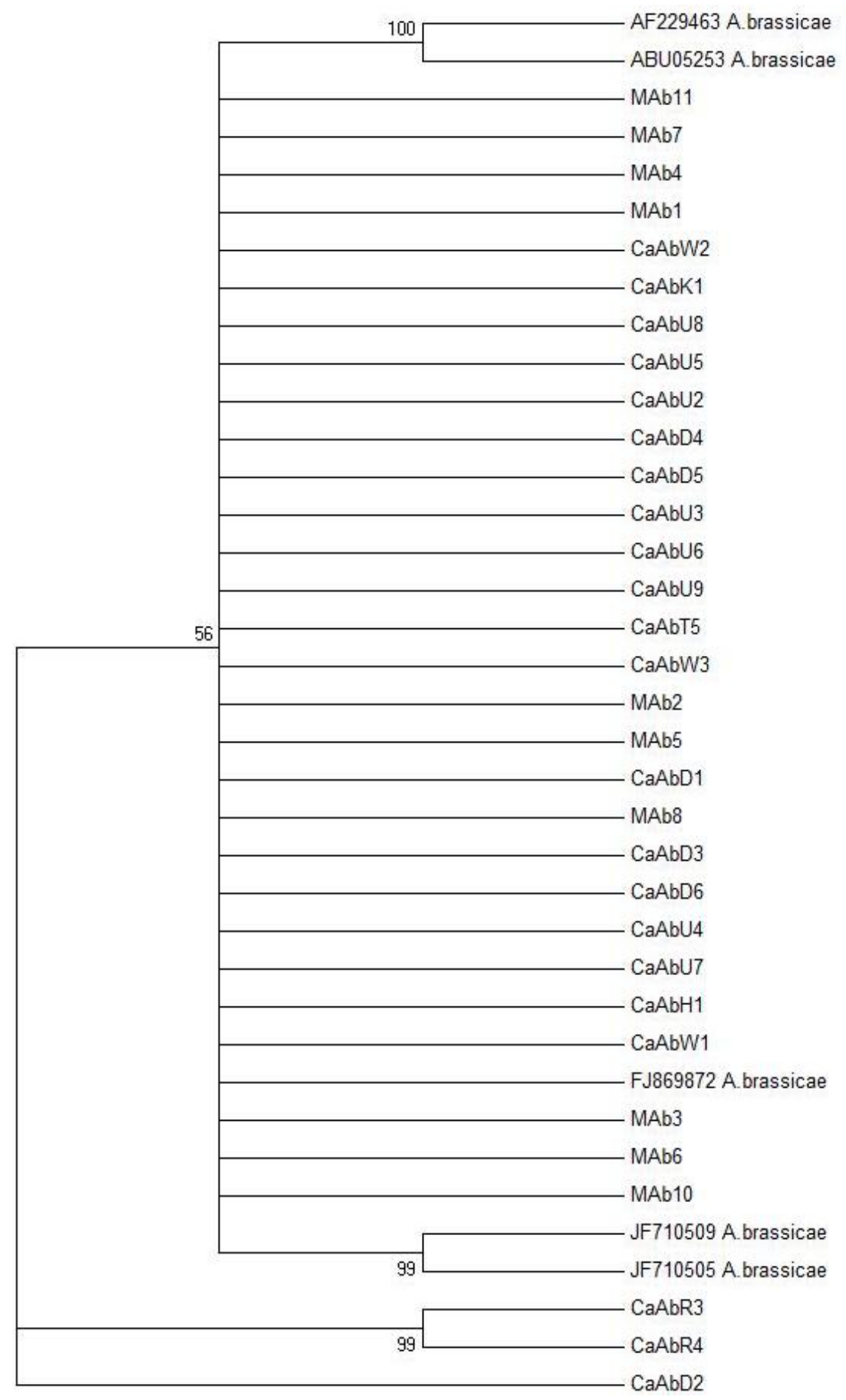

Figure 6. Dendrogram representing Internal Transcribed Spacer region of thirty two Alternaria brassicae isolates.

\section{REFERENCES}

Abul-Fazal M, Khan MI, Saxena SK (1994). The incidence of Alternaria species in different cultivars of cabbage and cauliflower seeds. Indian Phytopath. 47:419-421.

Altschul SF, Madden TL, Schaffer AA, Zhang J, Zhang Z (1997). Gapped BLAST and PSI-BLAST: a new generation of protein database search programs Nucleic Acids Res. 25: 3389-3402.
Ansari NA, Khan MW, Muheet A (1989). Effect of some factors on growth and sporulation of Alternaria brassicae causing Alternaria blight of rapeseed and mustard. Acta Bot. Ind. 17: 49-53.

Benali S, Mohamed B, Eddine HJ, Neema C (2011). Advances of Molecular Markers Application in Plant Pathology Research. Eur. J. Sci. Res. 50:110-123.

Berkenkamp B, Kirkham C (1989). Canola disease survey in N.E. Saskatchewan, 1988. Can. Plant Dis. Sur.69: 62. 
Chattopadhyay C (2008). Management of diseases of rapeseed mustard with special reference to Indian conditions. (in) Sustainable Production of Oilseeds: Rapeseed-Mustard Technology. Arvind Kumar, Chauhan J S and Chattopadhyay C (ed.). Agrotech Publishing Academy, Udaipur. pp. 364-388.

Chillali M, Wipf D, Guillaumin JJ, Mohammed C, Botton B (1998). Delineation of the European Armillaria species based on the sequences of the internal transcribed spacer (ITS) of ribosomal DNA. New Phytol. 138: 553-561.

Chou HH, Wu WS (2002). Phylogenetic analysis of internal transcribed spacer regions of the genus Alternaria and the significance of filament-beaked conidia. Mycol. Res. 106: 164-169.

Conn KL, Tewari JP (1990). Survey of Alternaria black spot and Sclerotinia stem rot in central Alberta in 1989. Can. Plant Dis. Survey 70:66-67.

David JC (1991). IMI Descriptions of Fungi and Bacteria No. 1075 Alternaria linicola. Mycopathologia116: 53-5.

Doyle JJ, Doyle JL (1990). Isolation of plant DNA from fresh tissue. Focus 12: 13-1.

Felsenstein J (1985). Confidence limits on phylogenies: An approach using the bootstrap. Evolution 39:783-791.

Gladers P (1987). Current status of diseases and. Control in winter oilseed rape in England and Wales. Bulletin SROP. 10: 7-10.

Goyal P, Chahar M, Mathur AP, Kumar A, Chattopadhyay C (2011). Morphological and cultural variation in different oilseed Brassica isolates of Alternaria brassicae from different geographical regions of India. Indian J. Agric. Sci. 81 (11): 1052-1058.

Hall TA (1999). BioEdit: a user-friendly biological sequence alignment editor and analysis program for Windows 95/98NT. Nucleic Acids Symposium Series 41: 95-98.

Jasalavich CA, Morales VM, Pelcher LE, Seguin-Swartz G (1995). Comparison of nuclear ribosomal DNA sequences from Alternaria species pathogenic to crucifers. Mycol. Res. 99:604 - 614 .

Jung DS, Na YJ, Ryu KH (2002). Phylogenic analysis of Alternaria brassicicola producing bioactive metabolites. J. Microbiol. 40:289294.

Kaur S, Singh G, Banga SS. (2007). Documenting variation in Alternaria brassicae isolates based on conidial morphology, fungicidal sensitivity and molecular profile. (in) Proceeding of the 12th International Rapeseed Congress, 26-30 March, Wuhan, China. 4: 87-9.

Kolte SJ (1985). Diseases of Annual Edible Oilseed Crops, RapeseedMustard and Sesame Diseases II. CRC Press, Boca Raton, FL, U.S.A.

Kumar R, Gupta PP (1994). Survival of Alternaria brassicae, A. brassicicola and $A$. alternata in the seed of mustard ( $B$. juncea) at different temperatures and relative humidities. Ann. Biol. 10:55-58.

Kusaba M, Tsuge T (1994). Nuclear ribosomal DNA variation and pathogenic specialization in Alternaria fungi known to produce hostspecific toxins. Appl. Environ. Microbiol. 60: 3055-3062.

Kusaba M, Tsuge T (1995). Phylogeny of Alternaria fungi known to produce host-specific toxins on the basis of variation in internal transcribed spacers of ribosomal DNA. Curr. Gen. 28: 491-498.

Meena PD, Awasthi RP, Chattopadhyay C, Kolte SJ, Kumar A (2010). Alternaria blight: a chronic disease in rapeseed-mustard. J. Oilseed Brassica 1: 1-11.

Meena PD, Chattopadhyay C, Kumar VR, Meena RL, Rana US (2005). Spore behaviour in atmosphere and trends in variability of Alternaria brassicae population in India. J Mycol Plant Pathol. 35: 511.

Nourani SL, Minassian V, Safaie N (2008). Identification, pathogenicity and distribution of Alternaria spp. of canola in Iran. Iranian J. Plant Pathol. 44: 33-36.

Patni CS, Kolte SJ, Awasthi RP (2005). Cultural variability of Alternaria brassicae, causing Alternaria blight of mustard. Ann. Plant Physiol. 19: 231-42.

Pattanamahakul P, Strange RN (1999). Identification and toxicity of Alternaria brassicicola, the causal agent of dark leaf spot disease of Brassica species grown in Thailand. Plant Pathol. 48:749-755.

Pryor BM, Gilbertson RL (2000). Molecular phylogenetic relationships amongst Alternaria species and related fungi based upon analysis of nuclear ITS and mt SSU rDNA sequences. Mycol. Res. 104: 3121321.
Saitou N, Nei M (1987). The neighbor-joining method: A new method for reconstructing phylogenetic trees. Mol. Biol. Evol. 4:406-425.

Sharma P, Deep S, Sharma M, Bhati DS (2013). Genetic variation of Alternaria brassicae (Berk) Sacc causing dark leaf spot of cauliflower and mustard in India. J. Gen. Plant Pathol. 79 (1): 41-45.

Simmons EG (1995). Alternaria themes and variations (112-144). Mycotaxon. 55:55-163.

Singh D, Singh R, Singh H, Yadav RC, Yadav N, Barbetti M, Salisbury P, Nimbal S, Chattopadhyay C, Kumar A (2007). Cultural and morphological variability in Alternaria brassicae isolates of Indian mustard (Brassica juncea L. Czern \& Coss.). (in) Proceeding of the 12th International Rapeseed Congress, 26-30 March, Wuhan, China 4: 158-60.

Tamayo MPJ, Becerra VDC, Jaramillo NJE (2001). Alternaria brassicae, agente causal de pudrición de la cabeza en coliflor (Brassica oleracea L. var. botrytis L). ASCOLFI Informa 27: 10-11.

Tamura K, Nei M, Kumar S (2004). Prospects for inferring very large phylogenies by using the neighbor-joining method. Proceedings of the National Academy of Sciences (USA). 101:11030-11035.

Tamura K, Peterson D, Peterson N, Stecher G, Nei M, Kumar S (2011). MEGA5: Molecular Evolutionary Genetics Analysis using Maximum Likelihood, evolutionary distance, and maximum parsimony methods. Mol. Biol. Evol. 28: 2731-2739.

Tewari JP (1983). Celular alterations in the black spot of rapeseed caused by Alternaria brassicae. Plant Pathol. 73: 831.

Tewari JP (1991). Structural and biochemical bases of the black spot disease of crucifers. Adv. Struct. Biol. 1:325-349.

Thompson JD, Gibson TJ, Plewnaik F, Jeanmongin F, Higgins DG (1997). The CLUSTAL windows interface: flexible strategies for multiple sequence alignment aided by quality analysis tools. Nucleic Acids Res. 24: 4876-4882.

Tosi L, Zezzerini A (1985). Septoria helianthi Ell. \& Kell. nuovo parassita del girasole in Italia. Inf. Fitopatol. 39: 43-44.

Varma PK, Singh S, Gandhi SK, Chaudhary K (2006). Variability among Alternaria solani isolates associated with early blight of tomato. Commun. Agric. Appl. Biol. Sci. 71: 37-46.

Verma PR, Saharan GS (1994). Monograph on Alternaria Diseases of Crucifers. Saskatoon Research Centre Technical Bulletin 1994-6E, Agriculture and Agri-Food Canada, Saskatoon, SK, Canada.

Weiss EA (1983). Oil seed crops. Longman, London, New York. pp-660. 